\title{
A DETERMINAÇÃO DE SENTIDOS LEXICAIS NO CONTEXTO
}

\author{
HERONIDES MAURÍLIO DE MELO MOURA \\ UFSC-CNPq ${ }^{1}$
}

\begin{abstract}
This article is an attempt to establish a link between types of anaphora with demonstrative pronouns and the way in which the determination of lexical meaning in context occurs. I intend to show that this analysis may highlight the nature of different kinds of indeterminacy of meaning, namely, polysemy, homonymy and vagueness.
\end{abstract}

\section{o INTRODUÇÃO}

Este artigo tenta estabelecer uma conexão entre tipos de anáfora com uso de demonstrativos e a forma como se dá a determinação de sentidos lexicais no contexto.

Esse tipo de correlação pode ser muito útil para a resolução de certos dilemas da semântica atual, como a diferença problemática entre polissemia e vagueza e o papel desempenhado pelo contexto na determinação de sentidos lexicais vagos e polissêmicos.

Pretendo mostrar que a análise de diferentes tipos de retomada anafórica com o uso de demonstrativos pode lançar luz sobre a natureza da diferença entre os itens lexicais vagos e polissêmicos e o papel diferenciado que desempenha o contexto na determinação do sentido lexical nesses dois tipos de indeterminação semântica. Além disso, essa análise pode ser útil também para a compreensão do processo de referenciação.

A vagueza e a polissemia são tipos de indeterminação semântica, e a diferença entre esses dois fenômenos não se reduz a um debate terminológico da semântica atual. O tipo de recorte a ser estabelecido entre a vagueza e a polissemia depende de uma série de decisões teóricas por parte do lingüista sobre, por exemplo, o papel reservado para a estrutura lexical e a função atribuída ao contexto na determinação dos sentidos lexicais. Essas decisões teóricas são fundamentais para a delimitação dos conceitos, pois no plano descritivo ainda não se tem evidências sobre onde se deve traçar a linha divisória entre as palavras vagas e as palavras polissêmicas.

\footnotetext{
${ }^{1}$ Gostaria de agradecer ao CNPq a bolsa de produtividade (Processo 521935/97-0) que possibilitou a realização dessa pesquisa.
} 
Este artigo pretende rever algumas das implicações teóricas da distinção entre polissemia e vagueza, assim como mostrar que elementos descritivos importantes para essa questão podem ser encontrados no estudo da anáfora. Para isso, descrevo três tipos de anáfora com o uso de demonstrativos, que se distinguem entre si pelas diferentes funções que neles desempenha o contexto, e procuro mostrar que o primeiro tipo, que caracteriza o esquema clássico de desambigüização, está associado a usos polissêmicos dos itens lexicais e que o terceiro tipo (retomada de um contexto de definição) está associado a usos vagos dos itens lexicais. O segundo tipo de anáfora analisado (quantificação de variável) é relevante por caracterizar uma função específica do contexto no processo de referenciação, mas não está ligado a uma forma específica de determinação dos sentidos lexicais.

$\mathrm{O}$ roteiro a ser seguido no artigo é o seguinte: na seção 1, apresento alguns critérios de identificação de três tipos (vagueza, polissemia e homonímia) de indeterminação semântica. A seguir, mostro a relevância e as implicações teóricas do recorte a ser estabelecido entre vagueza e polissemia. Na seção 2, apresento, com base em exemplos retirados de corpus informatizado, três tipos de retomada anafórica com o uso de demonstrativos e procuro fazer a correlação entre alguns desses tipos e as diferentes formas pelas quais se dá a determinação de sentidos lexicais no contexto.

\section{TIPOS DE INDETERMINAÇÃO SEMÂNTICA}

A indeterminação semântica ocorre quando a um item lexical corresponde mais de um sentido. Há vários tipos de casos em que isso ocorre, e às vezes não é fácil distinguir um tipo de outro. Vou examinar aqui dois critérios que nos permitam diferenciar os casos de polissemia, homonímia e vagueza. Os critérios são os seguintes: 1) obrigatoriedade de determinação no contexto; 2) lexicalização.

Mas, antes de especificar esses critérios, vamos considerar as definições de cada tipo de indeterminação semântica e as dificuldades que elas apresentam. De um modo geral, a polissemia é definida como a existência de mais de um sentido, associados a um item lexical e que mantêm entre si algum tipo de relação semântica. Assim, a palavra família é polissêmica, pois está associada a pelo menos três acepções que têm uma relação semântica entre si: a)a família nuclear, ou seja, pais e filhos; b)a família ampla e c) descendência, linhagem. Uma palavra como abafar também é polissêmica, pois no sentido literal significa 'tirar o ar, o oxigênio', mas no sentido metafórico pode significar 'esconder, ocultar', como em 'O governo abafou o escândalo.' Há assim dois tipos de polissemia: a literal e a metafórica. É muito comum que uma mesma palavra apresente os dois tipos de polissemia, a literal e a metafórica, como é o caso de artista, por exemplo. A palavra artista pode representar, no campo literal, várias significados: a)ator de televisão; b)cantor; c)artista plástico, etc, e no, campo metafórico, alguém é um artista se é cheio de artimanhas, manhoso.

Uma primeira distinção a ser feita é entre polissemia e homonímia. A homonímia normalmente é definida como 'a situação na qual um item lexical é associado com ao menos dois sentidos diferentes e sem relação entre si’ (Pustejovsky \& 
Boguraev:1996:2). A palavra banco é um exemplo clássico de homonímia: não há qualquer relação evidente entre os sentidos de instituição financeira e de assento. Um outro exemplo de homonímia é o substantivo corretor, significando tanto um instrumento de correção (por exemplo, corretor de texto) quanto agente comercial (por exemplo, corretor de imóveis). Às vezes não é simples distinguir polissemia de homonímia com base apenas na intuição e para evitar essa dificuldade necessitamos de critérios bem definidos.

Um outro tipo de indeterminação semântica é a vagueza. A vagueza ocorre quando o uso de uma palavra gera casos duvidosos de aplicação a certos seres ou situações. Um exemplo típico é a palavra bom. Qual a interpretação que devemos dar ao sintagma bom aluno, por exemplo? Diferentes interpretações podem ser evocadas num contexto: um bom aluno é aquele que demonstra inteligência, ou então é aquele que estuda muito, ou então é aquele que tem bom comportamento, etc. O sentido de bom aluno é compatível com todas essas interpretações; diz-se então que o adjetivo bom é vago, nesse sintagma. Vago aqui define essa situação em que uma palavra deixa em aberto diferentes interpretações. Muito se tem discutido se a vagueza é positiva ou negativa para a comunicação lingüística. A posição defendida aqui é que a vagueza dá flexibilidade e riqueza à linguagem.

Um outro tipo de palavras vagas são aquelas que envolvem uma escala de aplicação, gerando também casos duvidosos. Por exemplo, qual o limite para um acidente geográfico deixar de ser considerado um morro e passar a ser considerado uma montanha? Há uma vagueza evidente no limite de aplicação dessas palavras. O mesmo ocorre com os adjetivos gordo, rico, alto. Não há limites precisos de aplicação, no uso dessas palavras. Os itens lexicais podem então ser vagos em função de uma multiplicidade de critérios de definição (como nos casos das palavras bom e ruim, por exemplo) ou em função da indefinição dos limites da escala a que elas referem (como no caso dos adjetivos escalares como gordo, rico, alto, etc).

$\mathrm{O}$ critério de obrigatoriedade de determinação no contexto nos permite distinguir a homonímia da polissemia de uma maneira mais efetiva que as definições tradicionais. A idéia é que uma das acepções associadas ao item lexical homônimo deve necessariamente ser selecionada quando da ocorrência desse item num contexto, ao contrário da polissemia, quando mais de uma acepção podem co-ocorrer em determinados contextos.

Esse critério explica o funcionamento de alguns testes de ambigüidade propostos na literatura, entre eles o teste de identidade e o teste de zeugma (cf. Cruse, 2000). Esses testes foram propostos para aferir a incompatibilidade dos sentidos associados a um item lexical. O recorte a ser feito era entre a ambigüidade (polissemia e homonímia) de um lado e a vagueza de outro (cf. Kempson,1980). No entanto, entendo que esses testes captam uma condição mais fundamental que opõe a homonímia, de um lado, e a polissemia e a vagueza, de outro. Essa condição é justamente o critério de obrigatoriedade de determinação no contexto, que caracteriza a homonímia.

Esse critério está de acordo com a definição que Pinkal (1995) formula para a homonímia: uma expressão é homônima se e somente se um nível de base indeterminado é inadmissível. Em outras palavras, não há um sentido de base 
indeterminado (cf. Moura, 2001 ${ }^{\mathrm{a}}$ ) que seja compatível com os diferentes sentidos do termo homônimo.

Quanto mais distantes entre si, mais as acepções de uma palavra são incompatíveis entre si. Assim, no caso da homonímia, há uma incompatibilidade completa entre os sentidos de uma palavra, mas no caso da polissemia tal incompatibilidade pode ser maior ou menor. Esta incompatibilidade está ligada ao fato de que uma das acepções da palavra homônima deve necessariamente ser ativada no contexto, em oposição às outras acepções.

Consideremos brevemente os testes de identidade e de zeugma. O teste de identidade afirma que, no caso de sentidos incompatíveis, o uso da expressão (fazer isso) também exige obrigatoriamente a identidade dos sentidos que ela conecta. Vejamos o exemplo abaixo:

(1) João encontrou um corretor, e Paulo fez isso também.

A expressão fazer isso também impõe a identidade do possível sentido de corretor nas duas ocorrências dessa palavra. Ou seja, ou temos a situação em que tanto João quanto Paulo encontraram um instrumento de correção (por exemplo, um corretor de texto), ou então temos a situação alternativa em que tanto João quanto Paulo encontraram um agente comercial, um corretor de imóveis, por exemplo. Não é possível dar ao enunciado acima a interpretação de que, por exemplo, João encontrou um corretor de texto, e Paulo encontrou um profissional para vender seu imóvel. A homonímia do substantivo corretor bloqueia a leitura cruzada; uma só acepção é selecionada no contexto, em oposição à outra.

Esse funcionamento das palavras homônimas se diferencia do que acontece com as palavras polissêmicas e as palavras vagas. Considere por exemplo o substantivo livro: ele é polissêmico entre ao menos dois sentidos: a) o objeto físico (com folhas, capa, etc); b)o conteúdo que esse objeto físico contém. O substantivo livro é um caso típico de polissemia lógica, na terminologia de Pustejovsky (1995). Pois bem, tal substantivo não exige a identidade de sentidos no teste descrito acima:

(2) João gostou do livro, e o Paulo também.

É perfeitamente cabível interpretar essa sentença numa leitura cruzada, quer dizer, João pode ter gostado do conteúdo do livro e Paulo do seu acabamento gráfico, e esses sentidos não são incompatíveis entre si. Vejamos agora o exemplo (3):

(3) Maria é uma boa aluna e Pedro também.

A leitura cruzada também é possível no caso de palavras vagas como bom. Em (3), é possível interpretar o sentido de bom aluno diferentemente nos dois casos (em relação a Maria e em relação a Pedro). Por exemplo, Maria pode ser uma estudante inteligente e Pedro pode ser apenas bem comportado. A retomada anafórica de Pedro (é) também não envolve necessariamente o mesmo sentido de bom aluno atribuído na 
predicação de Maria (em Maria é uma boa aluna). Podemos ter interpretações distintas nas duas ocorrências de bom aluno.

Um outro teste que está ligado ao critério de obrigatoriedade de determinação no contexto é o teste de zeugma. Novamente aqui, apenas uma acepção é acessada, o que impede a conexão de sentidos diferentes por zeugma (elipse do verbo) no caso das palavras homônimas:

(4) João montou um cavalo, e Maria a peça de Shakespear.

Não é possível (a não ser talvez em alguns tipos de discurso, como o humorístico) coordenar por zeugma os sentidos de montar um cavalo (cavalgar) e montar uma peça (encenar), porque o contexto exige a determinação de apenas uma acepção, em oposição à outra. Assim, de acordo com o que se argumenta aqui, o verbo montar é um caso de homonímia, e não de polissemia, ao contrário do que dizem os dicionários (cf. Biderman (1984:10), que também mostra que os dicionários não são consistentes, quando consideram as diferentes acepções do verbo montar como um caso de polissemia e não de homonímia).

Em resumo, a desambigüização é necessária no caso da homonímia, mas não no caso da polissemia e da vagueza. Pinkal (1995:84) dá um exemplo interessante de como acepções diferentes de uma palavra polissêmica podem co-ocorrer num determinado contexto sem que isso acarrete qualquer problema na comunicação. Ele aborda as interpretações concreta e disposicional do adjetivo veloz, se aplicado ao substantivo carro, por exemplo. Se vejo um Porsche passando a $180 \mathrm{~km}$, e digo que esse carro é veloz, posso estar me referindo tanto à velocidade efetiva do carro (é a interpretação concreta), quanto à capacidade de andar velozmente que caracteriza esse automóvel (é a interpretação disposicional). Ora, essas duas interpretações são compatíveis com o enunciado 'esse carro é veloz', e não é preciso escolher, nesse contexto, uma das acepções associadas à palavra veloz. Esse funcionamento não seria possível no caso da homonímia.

O critério de obrigatoriedade de determinação no contexto separa duas classes de indeterminação semântica: de um lado, a homonímia, de outro a vagueza e a polissemia. O problema que resta é encontrar um critério diferenciador desses dois tipos de indeterminação. Os testes citados acima não permitem estabelecer uma distinção clara. Por exemplo, o teste de identidade, de acordo com Kempson (1980:132), mostraria que o verbo matar é vago e não ambíguo. Considere o exemplo (5) abaixo:

(5) João matou um pássaro, e Maria fez isso também.

Este enunciado pode descrever uma situação em que o malvado João matou um pássaro com uma espingarda de ar comprimido, ao passo que a inocente Maria matou um outro pássaro atropelando com sua bicicleta um ninho de passarinhos. Ou seja, no primeiro caso temos uma ação intencional, e no segundo caso uma ação nãointencional. Há então em jogo duas acepções do verbo matar e, de acordo com o teste 
de identidade, na interpretação de Kempson (1980:132), esse verbo deveria ser considerado como vago, ou seja, indefinido quanto ao traço de intencionalidade.

Existem, todavia, fortes argumentos para considerar o verbo matar como polissêmico. O teste de identidade, no caso desse verbo, é inconsistente com o teste de relações lexicais independentes, definido em Cruse (2000). Ao contrário do teste de identidade, o teste de relações lexicais independentes mostra que há uma oposição clara entre as duas acepções do verbo matar, pois na leitura do verbo matar como um ato intencional há uma relação de sinonímia com o verbo assassinar, ao passo que no caso da leitura do verbo matar como um ato não-intencional, essa relação de sinonímia não ocorre. Portanto, há duas acepções distintas associadas ao verbo matar, com relações lexicais independentes, mas que ao mesmo tempo estão ligadas entre si, o que é a condição definitória de polissemia.

O que parece acontecer é que o verbo matar apresenta duas acepções claramente distintas entre si, mas não a ponto de acarretar a obrigatoriedade de determinação no contexto de uma dessas acepções. Haveria assim uma escala de incompatibilidade entre as acepções dos itens lexicais indeterminados: numa ponta, o mais alto grau de incompatibilidade é representado pelas palavras homônimas, na outra ponta, o mais baixo grau é representado pelas palavras vagas, e num ponto intermediário se situam as palavras polissêmicas. No entanto, ainda precisamos de um critério consistente para separar, nessa escala, a polissemia da vagueza.

O critério sugerido aqui para fazer essa distinção é o da lexicalização (cf. Kleiber, 1999). A idéia é que há duas fontes diferentes de onde advêm os sentidos lexicais: o léxico e o contexto. Quando o sentido lexical acessado numa ocorrência está previamente disponível no léxico, dizemos que esse sentido é lexicalizado. Quando o sentido lexical é produzido no contexto, não ocorre lexicalização. A linha divisória entre polissemia e vagueza pode ser traçada a partir daí: no caso da polissemia (assim como no caso da homonímia), as diferentes acepções são lexicalizadas; no caso da vagueza, as diferentes acepções são derivadas diretamente do contexto. Assim, por exemplo, nada no léxico permite especificar qual acepção de bom aluno ou de aluno alto deve ser acessada numa determinada ocorrência. Na verdade, tal acepção deve ser buscada no contexto e não no léxico.

Desse modo, os critérios citados correspondem a duas linhas divisórias no fenômeno da indeterminação: em primeiro lugar, a obrigatoriedade de determinação no contexto separa de um lado a homonímia, e de outro a polissemia e a vagueza. Em segundo lugar, a lexicalização separa de um lado a homonímia e a polissemia, e de outro a vagueza. Esse quadro parece satisfatório à primeira vista, mas de fato não dispomos de testes seguros que nos permitam identificar a ocorrência ou não da lexicalização de um sentido lexical, ao contrário do que ocorre com o critério da obrigatoriedade de determinação no contexto. A oposição entre vagueza e polissemia é ainda uma questão em aberto na literatura sobre o assunto. A título de ilustração, considere os exemplos abaixo:

(6) João estava comendo coelho. 
(7) Depois que vários caminhões passaram sobre ele, tinha coelho espalhado por toda a pista.

Como Nunberg \& Zaenen (1997:13) indicam, não é fácil fazer a distinção entre lexicalização e uso contextual do sentido do substantivo coelho no exemplo (7) acima. A questão em jogo aqui é a oposição entre os sentidos contável e incontável associados a coelho. Na sentença (6), o substantivo coelho é usado na acepção incontável, e é razoável supor que essa acepção seja lexicalizada (cf Moura, 2000). No entanto, no caso da sentença (7), não é de modo algum claro se temos um sentido lexicalizado ou um sentido puramente contextual para uma interpretação incontável do substantivo coelho.

De algum modo, o sentido lexicalizado corresponde a uma cristalização do uso e é em função dessa cristalização que uma acepção é inserida num dicionário. No entanto, não se dispõe de um critério semântico razoável para identificar essas cristalizações do uso e opô-las a sentidos puramente contextuais.

Esses fatos mostram como seria importante encontrar alguma evidência empírica que permitisse a identificação da lexicalização. É esse objetivo que visamos com a análise da anáfora realizada na segunda seção desse artigo.

A oposição entre polissemia e vagueza é relevante não apenas do ponto de vista prático, mas principalmente do ponto de vista teórico. Do ponto de vista prático, ela permitiria ao lexicógrafo definir que acepções inserir na rede de acepções associadas a um item lexical. O postulado básico seria que as acepções de palavras vagas estão associadas ao contexto e ao conhecimento enciclopédico e como tal não devem ser arroladas como pertencentes ao léxico, ao passo que as acepções polissêmicas são lexicalizadas e devem ser arroladas pelo dicionário (cf. Rizzatti, 2001). Os dicionários são normalmente muito inconsistentes na representação dessa distinção e uma formulação teórica coerente poderia ser muito útil.

Mas um aspecto ainda mais vital são as questões teóricas envolvidas nessa distinção. A diferença entre a vagueza e a polissemia não se reduz a um debate terminológico da semântica atual. $\mathrm{O}$ tipo de recorte a ser estabelecido entre esses dois tipos de indeterminação semântica depende de uma série de decisões teóricas por parte do lingüista, sobre, por exemplo, o papel reservado para a estrutura lexical e a função atribuída ao contexto na determinação dos sentidos lexicais.

De um modo geral, a questão a ser abordada é a diferença entre o sentido lexical que é gerado pelo léxico (o caso da polissemia) e o sentido lexical que é gerado pelo contexto (o caso da vagueza). No debate semântico atual, há pelo menos duas visões divergentes sobre o modo como se dá a determinação de sentidos lexicais no contexto. Essas duas visões divergentes propõem papéis diferentes para o léxico e para o contexto. De um modo geral, ou elas propõem uma sobrecarga nas funções do léxico, ou uma sobrecarga na função do contexto. Assim, dependendo da perspectiva teórica, a polaridade da produção de sentidos lexicais se dirige para o léxico ou, alternativamente, para o contexto.

Em Moura $\left(2001^{\mathrm{b}}\right)$, denominei de 'visão polissêmica da indeterminação do sentido' a percepção teórica de que o léxico é o principal responsável pela 
determinação dos sentidos lexicais, embora o contexto desempenhe o papel de ativador dos sentidos lexicais previamente disponíveis no léxico, ou produzidos a partir de regras lexicais. Um modelo que representa muito bem essa visão é a teoria do léxico gerativo, desenvolvida por Pustejovsky (1995). Nesse modelo, o léxico contém uma série de regras que possibilitam a produção de sentidos lexicais nos diferentes contextos. Pustejovsky (1995:59) considera que os itens lexicais possuem diferentes dimensões de interpretação e uma interpretação particular é produzida num contexto determinado.

Nessa perspectiva, a idéia é que fatos estruturais estão na base da geração de sentidos específicos, e que há regras lingüísticas que determinam os sentidos lexicais acessados. Assim, a linha divisória entre polissemia e vagueza é muito clara, ao menos do ponto de vista teórico: a polissemia depende estritamente de condições estruturais lingüisticamente codificadas, ao passo que a vagueza, de caráter residual, é encarada como um fenômeno extra-lingüístico.

Por outro lado, há a perspectiva que denominei de 'visão vaga da indeterminação do sentido'. Nesse caso, a determinação de sentidos lexicais é vista como um procedimento essencialmente contextual, no qual a estruturação lexical tem um papel secundário. Um exemplo dessa visão é a Teoria da Precisificação (Pinkal,1995; Poesio,1995). Poesio (1995:171) propõe uma gramática com um léxico subespecificado, que contém predicados subespecificados. Uma função de interpretação atribui um valor a um item lexical subespecificado (vale dizer, indeterminado) a partir de uma situação discursiva. Assim, um verbo como montar seria subespecificado e receberia uma acepção específica quando associado a uma situação de discurso. A acepção específica (por exemplo, cavalgar ou encenar uma peça) deriva, nessa perspectiva, da situação discursiva. Nesse modelo, é o conjunto de situações discursivas, e não o léxico, que determina o conjunto de acepções. Em outras palavras, não haveria nenhum fato estrutural relativo ao léxico que produziria as diferentes acepções. Como é sempre a dinâmica do discurso que impõe a determinação do sentido lexical, não há, nessa 'visão vaga da indeterminação do sentido', uma diferença fundamental entre vagueza e polissemia, a não ser quanto ao tipo de relação que as diferentes acepções de uma palavra mantêm entre si (mais contínuas no caso da vagueza, mais descontínuas no caso da polissemia).

Assim, o que parece ocorrer é que a decisão teórica de enfatizar o léxico ou o contexto na determinação do sentido lexical é o elemento que define a forma como o recorte entre polissemia e vagueza é feito pelas diferentes teorias. Isso mostra a relevância teórica dessa diferença, mas mostra também que não dispomos de critérios semânticos independentes para fazer a distinção.

\section{TIPOS DE ANÁFORA COM O USO DE DEMONSTRATIVOS}

Koch, em artigo publicado neste número, arrola uma série de funções para o uso anafórico do demonstrativo, entre elas recategorização metafórica, uso polifônico, efeitos argumentativos, casos de hiperonímia, entre outros. A autora mostra que o uso 
dos demonstrativos é uma maneira muito rica e específica de efetivar o processo de referenciação. O que eu gostaria de mostrar aqui é que é possível definir diferentes tipos de anáfora com demonstrativos, a partir do papel que nelas desempenha o contexto. Por outro lado, alguns desses tipos de anáfora podem ser correlacionados às diferentes formas de determinação de sentidos lexicais no contexto.

Não parece haver dúvidas de que o contexto desempenha um papel fundamental na determinação dos sentidos lexicais num enunciado. No entanto, o que não está claro é em que consiste exatamente esse papel. A partir da análise dos dados, pretendo mostrar que, nas anáforas com uso de demonstrativo, há ao menos três funções diferentes que o contexto desempenha.

\subsection{Esquema clássico de desambigüizaçãa.}

A primeira função do contexto consiste no que denomino de esquema clássico de desambigüização, no qual o contexto fornece elementos que permitem ao interlocutor fazer a inferência sobre que sentido lexical deve ser acessado numa ocorrência específica do item lexical. Vejamos o exemplo (8) abaixo ${ }^{2}$ :

(8) "O que ocorre é que, quando uma policial revista um homem, essa revista acaba sendo apenas parcial", diz Vera Fávaro, 54.(Folha de São Paulo, 13/12/1994).

O contexto, nesse exemplo, fornece a informação de que se trata de uma situação de controle policial, sendo explicitamente citado o verbo revistar. Desse modo, não resta dúvida de que essa revista retoma o sentido de revista policial e não de revista na acepção de publicação periódica. Parece evidente aqui que o contexto desempenha um importante papel na determinação do sentido lexical, mas o que é menos notado é que o contexto não tem a função, nesse caso, de produzir um sentido lexical, mas apenas o de selecionar um sentido que é previamente dado. Em outras palavras, o léxico associa ao substantivo revista ao menos duas acepções, e esse é o elemento inicial da inferência que conduz à determinação do sentido lexical. O contexto fornece novas premissas que permitem chegar à seleção de uma das acepções inicialmente disponíveis no léxico.

O elemento inicial, que entra como premissa básica da inferência e que é logicamente anterior ao contexto, corresponde às acepções lexicalizadas. O importante aqui é compreender que a lexicalização é indispensável no processo de determinação de sentidos lexicais em exemplos como (8) acima. Se aceitamos que a lexicalização se faz presente nesse processo inferencial, então devemos concluir, caso o esquema proposto neste artigo esteja correto, que o substantivo revista é um caso de homonímia ou de polissemia, mas não um caso de vagueza, visto que há lexicalização, no substantivo revista, da acepção controle policial. De fato, os testes citados indicam que revista é um caso claro de homonímia (deixamos para o leitor a aplicação dos testes). Analisemos agora um exemplo com o substantivo jornal.

\footnotetext{
2 A maior parte dos exemplos analisados a partir daqui foram coletados no banco de dados do NILC (www.nilc.icmsc.sc.usp.br). Agradeço ao colega Marco Rocha a realização da busca de dados nesse corpus informatizado.
} 
(9) Na última terça-feira, o colunista Luís Nassif levantou questões pertinentes sobre o abuso dessa modalidade de investigação. Seu alvo eram as muitas reportagens abusivamente atribuídas à famosa equipe econômica. Aproveitei a deixa para anotar que a distorção afetava grande parte, talvez a maior, do noticiário sobre o governo Itamar-Cardoso. No caso deste jornal, sem que as reportagens respeitassem norma do "Novo Manual da Redação", que manda identificar o "off" com a expressão "a Folha apurou". (Folha de São Paulo, 25/12/1994).

O substantivo jornal apresenta polissemia lógica (cf. Pustejovsky,1995) entre ao menos duas acepções: (a) publicação, meio de comunicação; (b) exemplar dessa publicação. Essa ambigüidade é relevante em muitas situações, por exemplo, na frase 'João comprou o jornal', a acepção acessada é normalmente a de exemplar, a não ser que João seja um rico empresário que tenha condições de adquirir uma empresa de comunicação. Pois bem, a função do contexto em (9) é a de fornecer elementos que permitam selecionar uma acepção (a de publicação), que já estava previamente disponível no léxico. Note que em (8) o contexto exclui a possibilidade de escolha da acepção de exemplar, pois se trata de uma distorção no noticiário do jornal como um todo, e não apenas de um exemplar específico.

O importante a se ressaltar aqui é que temos um conjunto de acepções lexicalizadas que são logicamente anteriores, no processo de inferência, às pistas fornecidas pelo contexto. Nesse caso, não surpreende que o substantivo jornal, na literatura sobre o assunto, seja tratado como um caso de polissemia (pois envolve lexicalização) e não de vagueza (que não envolve lexicalização).

Em (09), a anáfora deste jornal retoma um referente específico (o jornal Folha de São Paulo), a partir da determinação de um sentido lexical específico.

\subsection{Quantificação de variável}

Uma segunda função do contexto em anáforas com uso do demonstrativo é totalmente distinta da primeira. Vejamos o exemplo (10) abaixo:

(10) Porém, quando a capital é instalada em uma pequena cidade, toda a vida econômica dessa cidade passa a depender da função de capital. Recentemente a capital da Alemanha foi transferida de Bonn para Berlim. Bonn, uma pequena cidade localizada às margens do Rio Reno, com apenas 300 mil habitantes, perdeu com isso suas atividades econômicas mais importantes. Os seus habitantes protestaram contra a mudança, que provocou a transferência de milhares de pessoas para Berlim. (texto identificado no NILC como didático/6serie/sociais/6geog1.txt).

A anáfora dessa cidade não retoma um referente extra-lingüístico específico, por exemplo Bonn ou outra cidade qualquer. No entanto, a retomada anafórica é fortemente contextualizada. De fato, há um referente construído discursivamente, representado sob a forma de uma variável quantificada. O exemplo (10) estabelece uma generalização do 
tipo: se $x$ é uma cidade pequena e uma capital é instalada em $x$, então a vida econômica de $x$ passa a depender de sua função de capital. A variável $x$ não designa uma cidade específica, mas qualquer cidade que tenha as características estabelecidas na generalização. Isso é obtido através da quantificação da variável (cf. McCawley, 1993:355-369 para uma discussão da natureza existencial ou universal do quantificador em questão). O referente discursivo representado pela variável é retomado anaforicamente pela expressão dessa cidade.

Desse modo, a função do contexto em (10), no uso do demonstrativo, é construir um referente discursivo através da quantificação de uma variável. Como se vê, trata-se de uma função inteiramente diversa daquela analisada nos exemplos (8) e (9). Vejamos um outro exemplo desse tipo de uso do demonstrativo, agora com a expressão essa família:

(11) No limite, o melhor índice para indicar a inflação que uma família paga é aquele resultante do acompanhamento da evolução dos preços dos bens e serviços que essa família compra a cada mês. Embora signifique muito para a família, sendo a forma ideal de medir seu poder de compra, não tem aplicabilidade geral. (Folha de São Paulo, 23/07/1994).

Novamente aqui, não se trata de uma família específica que é retomada pela expressão anafórica essa família, mas de um referente discursivo construído pela quantificação de uma variável. A generalização que se estabelece nessa referenciação pode ser representada da seguinte forma: para uma família $x$, o melhor índice da inflação para $x$ é o acompanhamento dos preços de bens e serviços que $x$ compra a cada mês.

\subsection{Retomada de um contexto de definição}

Analisemos agora a terceira função do contexto na anáfora com uso de demonstrativo. Nesse caso, não se trata de retomar um referente específico a partir da determinação de um sentido lexical previamente dado, como era o caso nos exemplos (8) e (9), nem de construir um referente discursivo a partir da quantificação de uma variável, como nos exemplos (10) e (11). A anáfora, nos casos que vamos analisar, parece retomar não um referente extra-lingüístico específico, mas um referente com um sentido inteiramente construído no discurso. Esse funcionamento só é possível, se minha hipótese está correta, porque os sentidos lexicais acessados não estão previamente disponíveis no léxico, ou seja, não são sentidos lexicalizados. Vejamos o exemplo (12) abaixo:

(12) Apesar das guerras de religião até meados do século XVII, esse cristianismo renovado foi, em seguida, implantado, tanto nas regiões católicas quanto protestantes, graças a uma melhor preparação do clero e a presença mais ativa da Igreja entre os fiéis, através, por exemplo, das visitas pastorais dos bispos em suas dioceses. (Texto identificado no NILC como corrigido/história/hist01.txt). 
A expressão anafórica esse cristianismo renovado caracteriza um funcionamento muito diferente do esquema clássico de desambigüização, em que o contexto permite a seleção de um sentido lexical previamente dado no léxico. Na expressão esse cristianismo renovado, que acepção lexicalizada de cristianismo seria selecionada? $\mathrm{O}$ cristianismo pode ser considerado renovado em razão de vários aspectos, e não se pode esperar que um dicionário seja capaz de enumerar todos eles (nem essa seria sua função). Somente o contexto pode definir em que sentido devemos interpretar a expressão cristianismo renovado e é a esse contexto de definição que faz referência a anáfora esse cristianismo renovado.

A minha hipótese é que esse funcionamento anafórico está ligado à natureza da indeterminação semântica do substantivo cristianismo. Como cristianismo é um substantivo vago e não polissêmico, então não há uma acepção lexicalizada que possa ser retomada pela expressão anafórica; o sentido lexical relevante é produzido no contexto.

Pode-se contra-argumentar que a expressão esse cristianismo renovado retoma simplesmente um referente extra-lingüístico definido culturalmente. Bem, mas como podemos ter acesso a esse referente sem fazer uso do contexto para determinar o seu sentido? Como afirma Marcuschi (em artigo neste número), a "determinação referencial prevê um processo de arbitragem interativamente controlado", de modo que, somente depois de os interlocutores negociarem, a partir do contexto, o sentido visado pelo falante, é que se pode determinar o referente e atribuir a ele uma realidade externa ao discurso.

Vejamos agora dois exemplos com o substantivo democracia, em que ocorre também a anáfora com retomada de um contexto de definição:

(13) Também identificando as duas tendências, o historiador Arthur Schlesinger Jr., exassessor de John Kennedy, sustenta a tese de que a história americana é moldada por ciclos: governos "liberais" e "sociais" se alternam no poder, produzindo, em escala histórica, um sistema eficaz de auto-regulagem. Ora, o que está em questão hoje é até mesmo essa democracia limitada ao mero jogo de alternância no quadro das elites. (Folha de São Paulo, 17-10-2000).

(14) Folha - Ao afastar preventivamente mais agentes da Abin, investigados numa sindicância, o general Alberto Cardoso, ministro-chefe do Gabinete de Segurança Institucional, não contribui para esclarecer o passado?

Cecília (Presidente do Tortura Nunca Mais- Rio) - Ele não quis dizer os nomes dos agentes para a sociedade brasileira. É um absurdo, estou indignada. São os mesmos esquemas da ditadura: o sigilo, o documento confidencial, secreto. Que democracia é essa? Como é que o presidente da República vem dizendo que tem horror à tortura? $\mathrm{O}$ mínimo que pode fazer, para começar a limpar a mancha que ficou em algumas instituições, nas Forças Armadas, por exemplo, é trazer a público esses nomes. (Folha de São Paulo, 18-12-2000). 
Em (13), o que é retomado pela expressão anafórica essa democracia não é a democracia de um país específico (no caso, os Estados Unidos), mas uma certa definição de democracia, construída no contexto. A anáfora tem aqui a função de reportar-se a um contexto de definição do item lexical, e é a partir desse contexto que se constrói um referente discursivo. O contexto, ao contrário do que ocorre no esquema clássico de desambigüização, não tem, neste tipo de anáfora que estamos considerando, apenas o papel de selecionar um sentido lexical previamente dado, mas o de construir um sentido para o item lexical em questão. De acordo com minha hipótese, esse funcionamento anafórico está ligado ao caráter vago do substantivo democracia.

O mesmo acontece no exemplo (14). Nesse exemplo, parece-me que o demonstrativo essa deve ser compreendido como se referindo não ao regime de um país específico (no caso, o Brasil), mas a uma certa definição de democracia, na qual instituições liberais convivem com 'esquemas da ditadura'. O que se questiona, na pergunta "que democracia é essa?" é a própria noção de democracia. Em outras palavras, o demonstrativo retoma um certo contexto de definição de democracia, definição esta que é posta em questão pelo locutor. Vejamos agora um exemplo com o substantivo universidade:

(15) O golpe militar de 1964 mostrou a que veio com a promulgação do Ato Institucional $\mathrm{n}^{\mathrm{o}}$ 5, em 13 de dezembro de 1968, e, em março do ano seguinte, Giannotti foi cassado, aposentado compulsoriamente de suas funções no departamento de filosofia da Universidade de São Paulo. A cassação interrompeu uma trajetória que Giannotti não fazia sozinho: como ele, boa parte dos intelectuais universitários estava engajada na construção não apenas de um novo modelo de universidade para o Brasil, mas de um novo país em que essa universidade pudesse ter seu lugar. (Folha de São Paulo, 17-12-2000).

Novamente aqui, a expressão anafórica não remete a um referente específico, mas a um certo conceito de universidade, a um contexto de definição. Note que o substantivo universidade pode ser também polissêmico, com as acepções de (a) instituição de ensino superior; (b) prédio no qual essa instituição se situa e (c) pessoal que nela trabalha ou estuda. Nesse caso, a determinação do sentido lexical dessa palavra pode se dar de acordo com o esquema clássico de desambigüização, na qual o contexto seleciona uma das acepções polissêmicas.

No entanto, além da polissemia, a palavra universidade pode também apresentar vagueza e é no contexto desse uso vago que a expressão anafórica do exemplo (15) funciona. A acepção em jogo em (15) é sem dúvida alguma instituição de ensino superior, mas vista sob uma certa ótica, um certo contexto de definição. É a esse conceito específico de instituição de ensino superior que se refere a expressão anafórica essa universidade.

Isso mostra que uma palavra pode ser polissêmica ou vaga em função do uso, mas isso não retira a importância da distinção entre polissemia e vagueza. Ao contrário, os tipos de anáfora que estamos analisando mostram que existem evidências de que o 
processo de determinação de sentidos lexicais de palavras com usos vagos se diferencia daquele de palavras com usos polissêmicos.

Para finalizar, vejamos um exemplo que não é retirado de um corpus, mas que é relevante justamente por estar fora de contexto, o que gera uma ambigüidade muito interessante para nossa análise:

(16) Não é nessa universidade que eu gostaria de trabalhar.

Uma primeira interpretação seria aquela na qual a expressão nessa universidade remete a uma universidade específica. Nesse caso, teríamos o processo clássico de desambigüização, no qual uma acepção lexicalizada é selecionada (no caso, instituição de ensino superior) e a partir disso um referente específico é escolhido no universo do discurso.

Uma segunda interpretação seria aquela na qual a expressão nessa universidade remete não a uma universidade específica, mas a um contexto de definição do substantivo universidade. Como nos falta esse contexto de definição no exemplo (16), não podemos saber de que conceito de universidade se trata, mas podemos perfeitamente imaginar um contexto no qual o locutor esteja se referindo, por exemplo, ao modelo de universidade imaginado pelo governo federal. Nesse caso, a expressão nessa universidade estaria se referindo a esse contexto de definição e não a uma universidade específica.

A ambigüidade do exemplo (16) mostra que há claramente uma oposição entre dois funcionamentos da anáfora com uso do demonstrativo, e a hipótese que foi defendida neste artigo indica que o primeiro funcionamento está associado a um uso polissêmico da palavra universidade e que o segundo funcionamento está associado a um uso vago dessa palavra.

\section{$\overline{\text { REFERÊNCIAS }}$}

BIDERMAN, M. T. C. (1984). A ciência da lexicografia. Alfa 28:1-26

CRUSE, A. (2000). Aspects of the micro-structure of word meanings. In RAVIN, Y. \& LEACOCK, C. Polysemy. Theoretical and computational approaches. Oxford, Oxford Press.

KEMPSON, R. (1980). Teoria semântica. Rio de Janeiro, Zahar.

KLEIBER, G. (1999). Problèmes de Sémantique - la polysémie en questions. Villeneuf d'Ascq, Presses Universitaires du Septentrion.

KOCH, I. (2001). A referenciação como atividade cognitivo-discursiva e interacional. Neste número.

MARCURSCHI, L. (2001). Atos de referenciação na interação face a face. Neste número.

McCAWLEY, J. (1993). Everything that linguists have always wanted to know about logic. Chicago, University of Chicago Press. 
MOURA, H. (2000). Resenha de Problèmes de Sémantique (G. Kleiber). DELTA 16 (2): 431-442. . $\left(2001^{\mathrm{a}}\right)$. Dénotation et argumentation dans le discours. Langages, 142:77-91.

. $\left(2001^{b}\right)$. Polysemy and vagueness. Palestra apresentada na Conferência sobre polissemia e indeterminação semântica, Florianópolis.

NUNBERG, G. \& ZAENEN, A. (1997). La polysémie systématique dans la description lexicale. Langue française 113: 12-23.

PINKAL, M. (1995). Logic and Lexicon. Dordrecht, Kluwer.

POESIO, M. (1995). Semantic ambiguity and perceived ambiguity. In K. van Deemter \& S. Peters (eds.) Semantic ambiguity and underspecification. Stanford, CSLI Publications.

PUSTEJOVSKY, J. (1995). The Generative lexicon. Cambridge, MIT Press.

PUSTEJOVSKY. J. \& BOGURAEV, B. (1996). Lexical semantics. The problem of polysemy. Oxford, Clarendon Press.

RIZZATTI, C. (2001). O que cabe num dicionário: uma questão polissêmica. Dissertação de mestrado, UFSC. 